\title{
Formability of stamping magnesium-alloy AZ31 sheets
}

\author{
Fuh-Kuo Chen*, Tyng-Bin Huang \\ Department of Mechanical Engineering, National Taiwan University, Section 4, No. 1, Roosevelt Road, Taipei, Taiwan, ROC
}

Received 29 August 2002; received in revised form 27 April 2003; accepted 15 May 2003

\begin{abstract}
In the present study, the formability of stamping magnesium-alloy AZ31 sheets at elevated temperatures was investigated by conducting various experiments. The experimental results indicate that AZ31 sheets exhibit poor formability at room temperature, but the formability is improved significantly at elevated temperatures. Also the springback is reduced when AZ31 sheets are stamped at higher temperatures. In addition, the conical cup value (CCV) tests performed in the present study reveal that an optimum forming temperature, which is below $400{ }^{\circ} \mathrm{C}$, exists, and a lower forming temperature should be applied in the actual forming process. The experimental results obtained in the present study provide the fundamentals for the stamping die design of forming AZ31 sheets.
\end{abstract}

(c) 2003 Elsevier B.V. All rights reserved.

Keywords: Magnesium-alloy AZ31 sheet; Formability; High temperature properties

\section{Introduction}

Due to its lightweight and high specific strength, magnesium-alloy has been widely used for structural components, notably in the automotive industry [1]. Although the principal manufacturing process has been die casting, the press forming has considerable potential because of its competitive productivity and performance. Among the fabrication processes of press forming, stamping of magnesium-alloy sheets is especially important for the production of thin-walled structural components. Since the magnesium-alloy usually exhibits limited ductility at the room temperature due to its hexagonal close-packed (HCP) structure, the mechanical properties of magnesium-alloy can be improved at elevated temperatures [2-6]. However, literature regarding stamping magnesium-alloy sheets is not profound, and the stamping process of magnesium-alloy is not well developed to date [7-12]. A variety of magnesium-alloys have been applied to manufacture structural components. As for press forming, AZ31 is considered as the suitable magnesium-alloy for the stamping process at the present time.

In the present study, the formability of stamping magnesium-alloy AZ31 sheets was investigated using the experimental approach. The mechanical properties of magnesium-alloy AZ31 sheets at various temperatures rang-

\footnotetext{
* Corresponding author. Tel.: +886-2-3621-522; fax: +886-2-3631-755. E-mail address: fkchen@ccms.ntu.edu.tw (F.-K. Chen).
}

ing from room temperature to $400{ }^{\circ} \mathrm{C}$ were obtained from experimental results. In addition, the important forming characteristics of AZ31 sheets, such as forming limit, conical cup value (CCV), springback and minimum bending radius, were also examined by experiments.

\section{Mechanical properties tests at elevated temperatures}

The stress-strain relations are the basic information for the study of formability of a sheet metal. Since magnesium-alloy exhibits poor formability at room temperature, tensile tests at various temperatures ranging from room temperature to $400^{\circ} \mathrm{C}$ were performed in the present study. The tensile test specimens made of AZ31 sheets of $1.2 \mathrm{~mm}$ thickness were prepared according to the ASTM standards. The specimens were cut along planes coinciding with the rolling direction $\left(0^{\circ}\right)$ and at angles of $45^{\circ}$ and transverse $\left(90^{\circ}\right)$ to the rolling direction. The cut edges were polished to avoid fracture occurring at an undesired location of the specimen.

In order to perform tensile tests at elevated temperatures, a heating furnace was mounted on the MTS810 test machine. The specimens were heated to $100,200,300$ and $400{ }^{\circ} \mathrm{C}$ before the tensile tests were performed. During tests, the temperature of specimen was kept constant until the specimen was stretched to failure.

The stress-strain relations for AZ31 at room temperature obtained from specimens in the three different orientations 


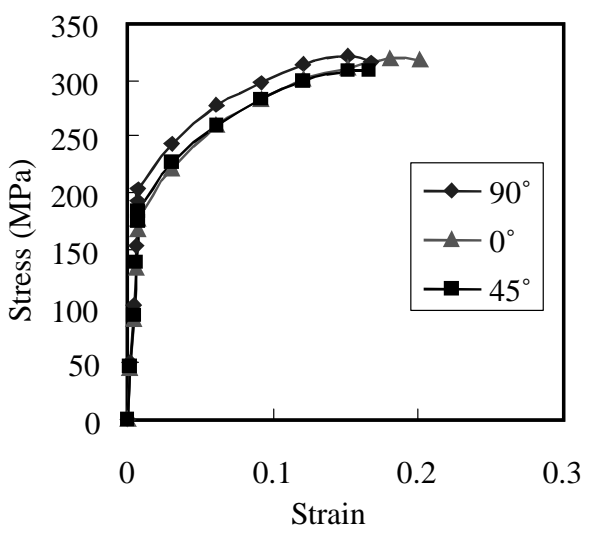

Fig. 1. Stress-strain relations at room temperature.

is shown in Fig. 1. It is seen in Fig. 1 that the specimen endured very small elongation before fracture. The maximum elongation is less than $20 \%$. This indicates that AZ31 bears poor formability at room temperature. It also seen that the material does not show significant anisotropy at room temperature since all three curves are close to one another. In order to show the average stress-strain relations, the average flow stress $\bar{\sigma}$ calculated from $\bar{\sigma}=\left(\sigma_{0}+2 \sigma_{45}+\sigma_{90}\right) / 4$ for each measured strain was adopted to plot the stress-strain relations. Fig. 2 shows the stress-strain relations of AZ31 at various temperatures. It is clearly seen in Fig. 2 that the yield stress drops significantly as the temperature increases. Also the elongation of specimen reaches to $58 \%$ at $400^{\circ} \mathrm{C}$. It is confirmed from Fig. 2 that AZ31 exhibits excellent formability at elevated temperatures. It is also noted in Fig. 2 that the work-hardening effect becomes insignificant as the test temperature increases. Since the work-hardening coefficient, $n$, is usually considered as an index whether sheets are deformed uniformly or not, the lower $n$ value indicates that the uniform deformation in the thickness direction is not easy to achieve at high temperature for AZ31 sheets.

From the tensile test results, it can be inferred that AZ31 may not be formed at room temperature, but as long as the sheet is heated to elevated temperatures, forming becomes possible.

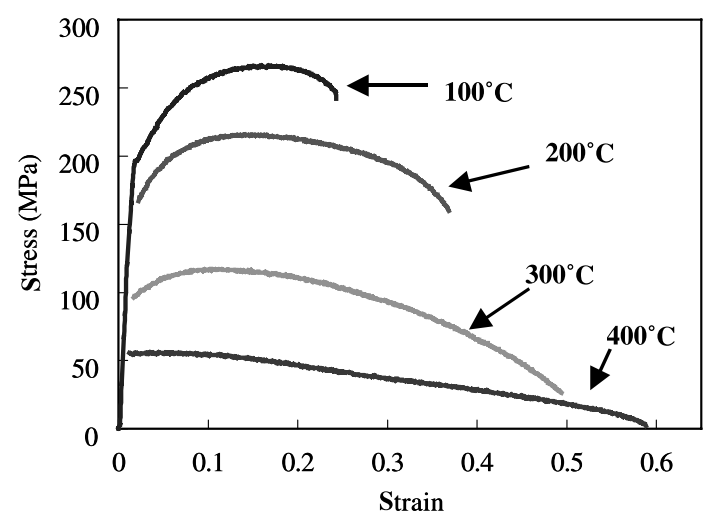

Fig. 2. Stress-strain relations at elevated temperatures.

\section{Stamping formability at elevated temperatures}

In addition to the basic mechanical properties, the stamping formability of AZ31 sheets were also examined at elevated temperatures. In the present study, the forming limit tests, CCV tests, springback tests, and minimum bending radius tests were performed. These tests represent the stamping properties in a sheet-metal forming process.

\subsection{Forming limit tests}

Since Keeler and Backofen [13] introduced the concept of forming limit diagram (FLD) in 1963, it has been a widely accepted criterion for fracture prediction in the sheet-metal forming. To determine a FLD, stretching tests were performed for sheet-metal specimens of different widths using a semi-spherical punch. The specimens were first electrochemically etched with circular grids that would be deformed into ellipses after being stretched. The engineering strains measured in the major- and minor-axes of the ellipse are termed the major and minor strains, respectively. They are also the principal strains on the plane where the strains are measured.

In the present study, rectangular specimens having the same length of $140 \mathrm{~mm}$, but with different widths ranging from 20 to $140 \mathrm{~mm}$ in an increment of $20 \mathrm{~mm}$, were tested. Similar to the tensile tests, the AZ31 sheet was cut at three orientations to the rolling direction, i.e. 0,45 , and $90^{\circ}$, for each size of specimen. During the tests, specimens clamped at the periphery were stretched to failure over a $78 \mathrm{~mm}$ semi-spherical punch. The engineering major and minor strains measured in the location closest to the fracture for each specimen were recorded. The major and minor strains were plotted against one another with the major strain as the ordinate, and the curve fitted into the strain points was defined as the forming limit curve. The diagram showing this forming limit curve is called the forming limit diagram. The FLD is a very useful criterion for the prediction of the occurrence of fracture in a stamping process.

For the forming limit tests conducted at elevated temperatures, the heating oven used in the tensile tests was mounted in the same test machine enclosing both die and punch, i.e. the tooling and specimens were heated at the same time and were kept at the same temperature. Fig. 3 shows the fractured specimens tested at various temperatures. It is seen in Fig. 3 that the specimen tested at a higher temperature has a greater depth of drawing. The forming limit curves for specimens tested at 100,200 , and $300^{\circ} \mathrm{C}$ are shown in Fig. 4. In FLD, the higher the forming limit curve, the better is the formability. As seen in Fig. 4, the specimen tested at a higher temperature clearly possesses a higher curve. This means that sheet is not easy to fracture at high temperature and has better formability. The trend showing in the forming limit test results agrees very well with the results obtained in the tensile tests. 


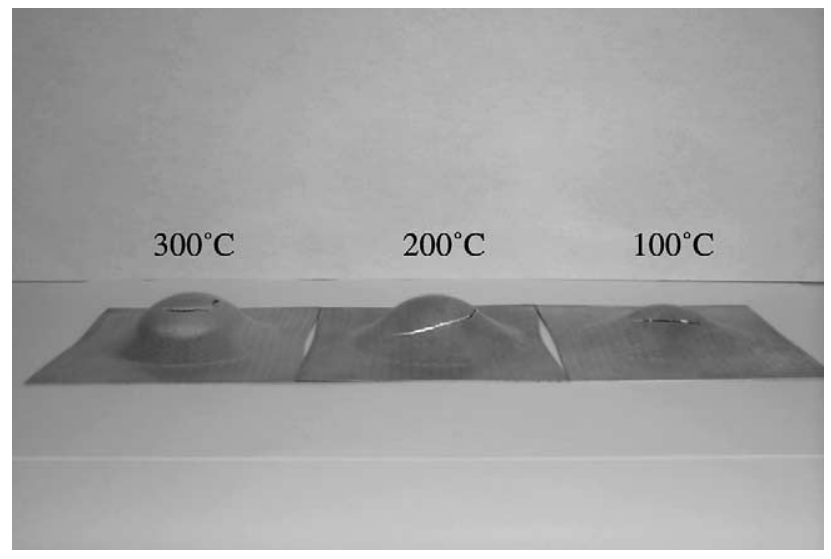

Fig. 3. Fractured specimens in the forming limit tests at elevated temperatures.

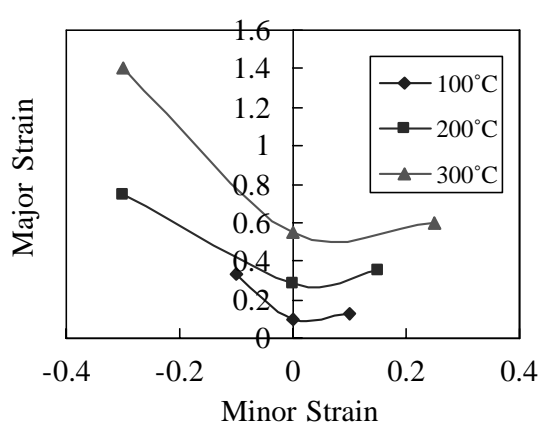

Fig. 4. The forming limit curves at elevated temperatures.

\subsection{CCV tests}

In a CCV test, a circular sheet blank with a specified diameter is placed on the top of a die, which has a conical cavity at center as shown in Fig. 5. A punch with a circular head, as shown in Fig. 5, then moves down to deform the sheet blank to fracture. The diameter of the top of the fractured conical cup is measured, and is defined as the CCV. For a circular blank with a specified diameter, a smaller value of CCV implies a larger drawing depth, resulting in better formability. In the present study, CCV tests were performed according to the JIS Z2249 standard. Circular specimens with a diam-

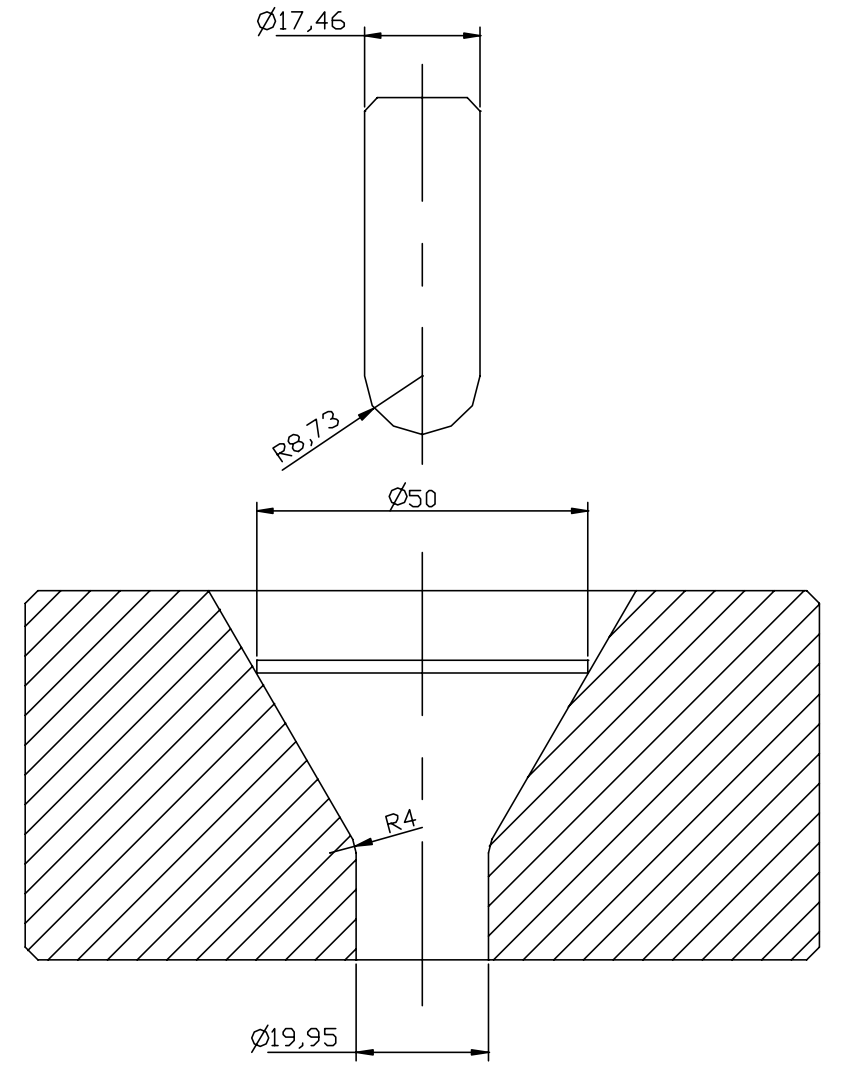

Fig. 5. Punch and die used in the CCV tests (unit: $\mathrm{mm}$ ).

eter of $50 \mathrm{~mm}$ were cut from $0.85 \mathrm{~mm}$ thick AZ31 sheets. The dimensions of die and punch are also shown in Fig. 5. It is to be noted in Fig. 5 that there is no blank-holder used in the CCV test, and the test is of free drawing. Hence, the effect of blank-holder force is excluded in the test.

The same heating apparatus used in the forming limit tests was used for the CCV tests at elevated temperatures of $100,200,300$, and $400{ }^{\circ} \mathrm{C}$. The fractured conical cups obtained from various temperatures are shown in Fig. 6. It is seen in this figure that the depth of drawing increases as the increase of temperature. However, the maximum drawing depth occurred at $300{ }^{\circ} \mathrm{C}$ instead of $400{ }^{\circ} \mathrm{C}$ as shown in Fig. 6. This phenomenon can be easily seen from the CCV plotted in Fig. 7. As noted in Fig. 7, the CCV decreases as the

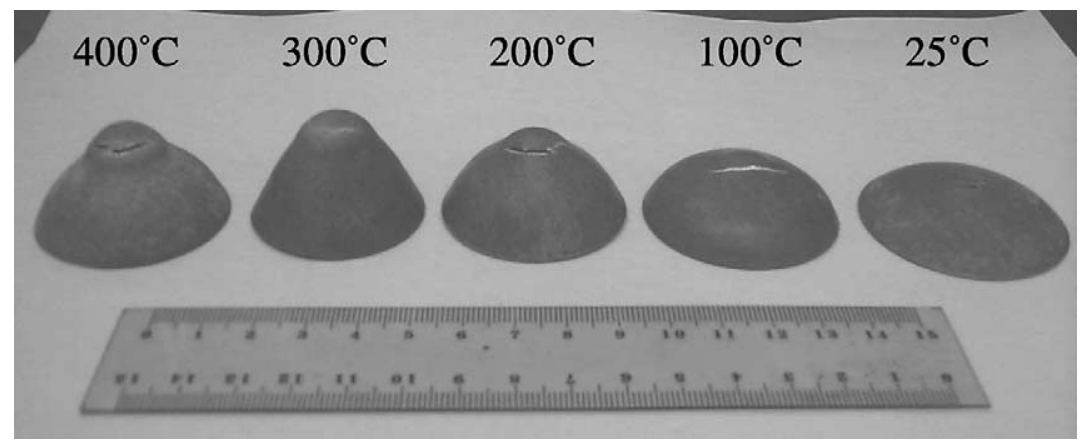

Fig. 6. Fractured conical cups obtained from various temperatures. 


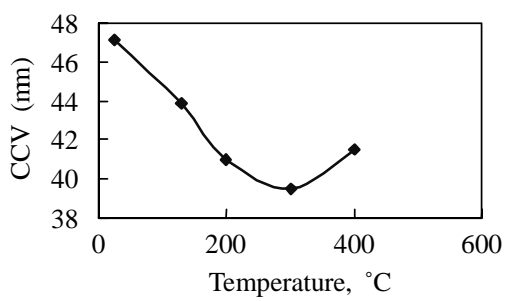

Fig. 7. $\mathrm{CCV}$ at various temperatures.

temperature increases, and reaches to a minimum value of $39 \mathrm{~mm}$ at $300^{\circ} \mathrm{C}$. As the temperature increased to $400^{\circ} \mathrm{C}$, the $\mathrm{CCV}$ did not decrease continuously, and on the contrary, the CCV was increased to $41.5 \mathrm{~mm}$. This opposite trend provides an important information on the formability of AZ31 sheets at elevated temperatures that an optimum forming temperature exists within the temperature range lower than $400{ }^{\circ} \mathrm{C}$, and not simply the higher temperature, the better formability.

The inferior formability of AZ31 sheets at $400{ }^{\circ} \mathrm{C}$ may be attributed to the low value of work-hardening coefficient, $n$, as indicated in the mechanical properties tests. Although the yield stress is quite low for AZ31 sheet at $400{ }^{\circ} \mathrm{C}$, the low value of $n$ induces local deformation at the punch head that causes fracture. Therefore, the CCV test results suggest that the AZ31 sheets can be stamped below $400^{\circ} \mathrm{C}$.

\subsection{V-bend tests}

Since magnesium-alloy has a lower value of elastic modulus than that of steel, springback could be much significant in a bending process. In the present study, V-bend tests were performed to examine the springback property of an AZ31 sheet at room temperature and elevated temperatures. The tooling used in the V-bend tests is shown in Fig. 8. It can be seen in Fig. 8 that the lower die has a opening angle of $90^{\circ}$, and the tooling is enclosed in a heating furnace. In order to study the effect of punch radius on the springback, the tooling sets with punch radii from 0.3 to $7.2 \mathrm{~mm}$, in an increment of $0.6 \mathrm{~mm}$, were prepared. The AZ31 sheets

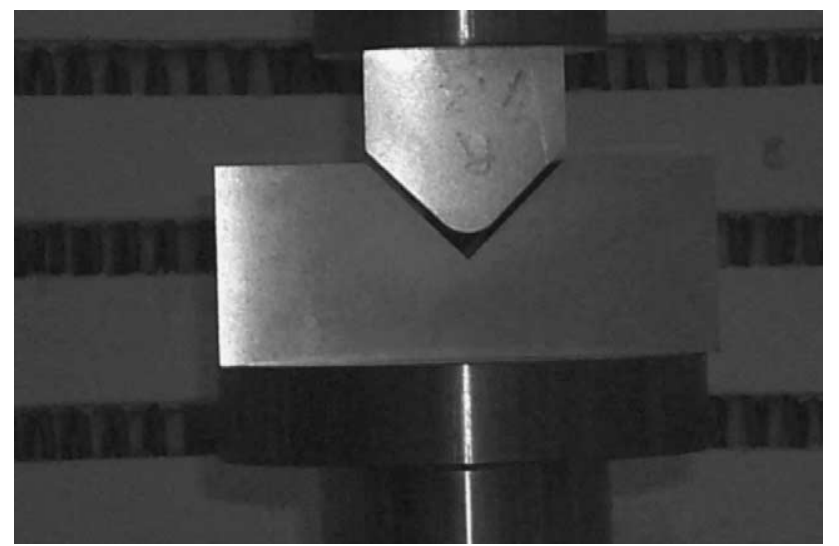

Fig. 8. Tooling used in V-bend tests.

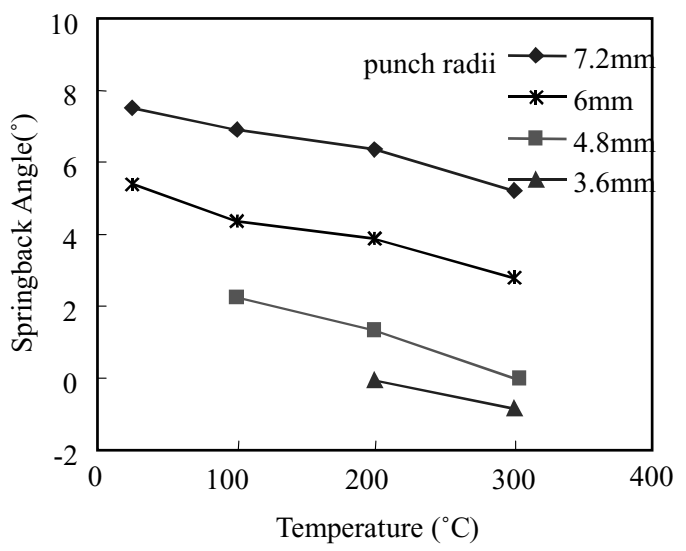

Fig. 9. Relationship between springback and forming temperature.

with a thickness of $1.2 \mathrm{~mm}$, a length of $60 \mathrm{~mm}$, and a width of $15 \mathrm{~mm}$ were used as specimens. The bending tests were conducted at room temperature, 100,200 , and $300^{\circ} \mathrm{C}$. After bending tests, the angles of bent specimen were measured by a CMM.

Fig. 9 shows the relationship between springback and forming temperature for various punch radii. It is seen in Fig. 9 that the springback decreases as the forming temperature increases regardless of the punch radius. It indicates that the AZ31 sheet not only has better formability but also exhibits less springback at higher forming temperatures. It is well known that the springback is affected by both the elastic modulus and the yield stress of the material. Since the elastic modulus does not vary too much with the change of temperature, and the yield stress of AZ31 sheet decreases with the increase of temperature, the decrease of springback at higher forming temperatures is due to the lower yield stress of AZ31 at elevated temperatures.

The effect of punch radius on the springback is shown in Fig. 10. It is observed in Fig. 10 that the springback decreases for smaller punch radii regardless of temperature change. The smaller punch radius causes larger plastic deformation

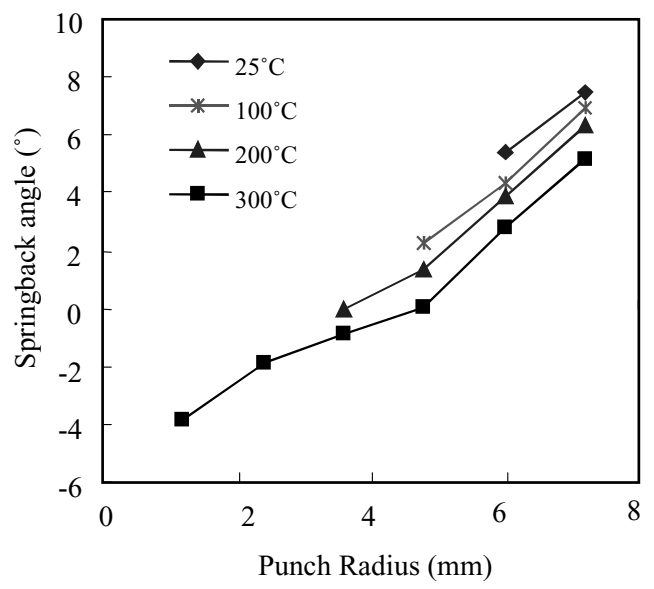

Fig. 10. The effect of punch radius on springback. 


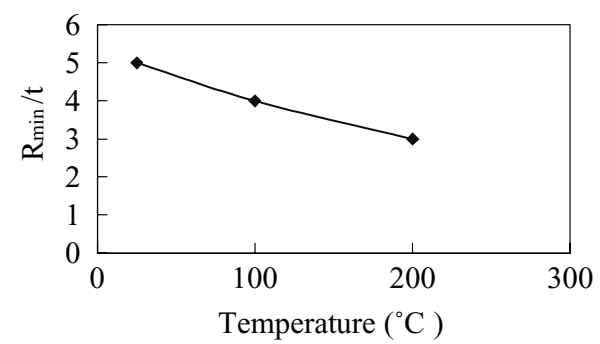

Fig. 11. Minimum bending radius at various temperatures.

at the bend, and hence reduces the effect of springback. This deformation mode is the same for AZ31 sheets being deformed at various temperatures, as seen in Fig. 10. It is to be noted in both Figs. 9 and 10 that negative values of springback occur for smaller punch radii. This is because that the sheet on the straight sides of V-shape is deformed into an arc at the beginning of bending process, and the load applied to flatten the arc at the end of bending process results in a complex stress distribution that causes the negative value of springback [14].

It is also to be noted in Fig. 10 that there exists a minimum bending radius for AZ31 sheet at each forming temperature, and the value of minimum bending radius decreases as the temperature increases. This relationship is shown in Fig. 11. It is seen in Fig. 11 that the minimum bending radius for $1.2 \mathrm{~mm}$ thick AZ31 sheet is about $3.6 \mathrm{~mm}$ at forming temperature of $200^{\circ} \mathrm{C}$.

\section{Conclusions}

The stress-strain relations indicate that AZ31 sheets have higher yield stress and smaller elongation at room temperature, but the yield stress drops significantly when the sheet is heated to a temperature higher than $200^{\circ} \mathrm{C}$. The work-hardening coefficient, $n$, also drops at elevated forming temperatures. From the point view of formability, AZ31 sheets exhibit good formability but greater possibility of local deformation at elevated forming temperatures. The forming limit tests also show the same trend as that shown in the stress-strain relations at various forming temperatures. Similar tend can be found in the test results of minimum bending radius of AZ31 sheets. This means that AZ31 sheets can sustain more deformation before fracture at elevated forming temperatures.

The CCV tests reveal that an optimum forming temperature exists and the temperature is below $400{ }^{\circ} \mathrm{C}$ for AZ31 sheets. The V-bend tests also provide an important informa- tion that the springback can be reduced at elevated forming temperatures.

\section{Acknowledgements}

The authors would like to thank the National Science Council of the Republic of China for financially supporting this research under Contract No. NSC 89-2212-E-002-147, which makes the experimental work possible. They also would like to thank Mr. Kuan-Hua Chiu and Mr. Chi-Kuen Chang for their help in tooling design.

\section{References}

[1] B.L. Mordike, T. Ebert, Magnesium properties-applicationpotential, Mater. Sci. Eng. A 302 (2001) 37-45.

[2] H. Watanabe, H. Tsutsui, T. Mukai, M. Kohzu, S. Tnabe, K. Higashi, Deformation mechanism in a coarse-grained $\mathrm{Mg}-\mathrm{Al}-\mathrm{Zn}$ alloy at elevated temperatures, Int. J. Plast. 17 (2001) 387-397.

[3] K. Kitazono, E. Sato, K. Kuribayashi, Internal stress superplasticity in polycrystalline AZ31 magnesium alloy, Scripta Materialia 44 (2001) 2695-2702.

[4] J. Kaneko, M. Sugamata, M. Numa, Y. Nishikawa, H. Takada, Effect of texture on the mechanical properties and formability of magnesium wrought materials, J. Jpn. Instit. Met. 64 (2) (2000) 141-147.

[5] A. Mwembela, E.B. Konopleva, H.J. McQueen, Microstructural development in $\mathrm{Mg}$ alloy AZ31 during hot working, Scripta Materialia 37 (11) (1997) 1789-1795.

[6] H. Takuda, H. Fujimoto, N. Hatta, Modeling on flow stress of $\mathrm{Mg}-\mathrm{Al}-\mathrm{Zn}$ alloys at elevated temperatures, J. Mater. Proc. Technol. 80-81 (1998) 513-516.

[7] E. Doege, K. Droder, Sheet metal forming of magnesium wrought alloys-formability and process technology, J. Mater. Proc. Technol. 115 (2001) 14-19.

[8] H. Somekawa, M. Konzu, S. Tanabe, K. Higashi, The press formability in magnesium alloy AZ31, Mater. Sci. Forum 350-351 (2000) 177-182.

[9] H. Takuda, T. Yoshii, N. Hatta, Finite-element analysis of the formability of a magnesium-based alloy AZ31 sheet, J. Mater. Process. Technol. 8990 (1999) 135-140.

[10] T. Ohwue, S.I. Sekiguchi, M. Kikuchi, S. Itoh, Formability of AZ31 magnesium alloy sheets under warm working conditions, J. JSTP 42 (482) (2001-2003) 246-248.

[11] N. Koga, R. Paisarn, Oil-free deep drawing of AZ31 magnesium alloy sheets using hard thin-film-coated tools, J. JSTP 42 (481) (2001-2002) 145-149.

[12] S. Aida, H. Tanabe, H. Sugai, I. Takano, H. Ohnuki, M. Kobayashi, Deep-drawability of cup on AZ31 magnesium alloy plate, J. Jpn. Instit. Light Met. 50 (9) (2000) 456-461.

[13] S.P. Keeler, W.A. Backofen, Plastic instability and fracture in sheets stretched over rigid punches, Trans. Am. Soc. Met. 56 (1963) 25-48.

[14] A. Forcellese, L. Fratini, F. Gabrielli, F. Micari, The evaluation of springback in 3D stamping and coining processes, J. Mater. Process. Technol. 80-81 (1998) 108-112. 